\title{
$\left(\mathrm{TCTA} / \mathrm{TCTA}_{1 / 3} \mathrm{TAZ}_{2 / 3} / \mathrm{TAZ}\right): \operatorname{Ir}(\mathrm{ppy})_{3}$ 발광층을 이용한 고효율 녹색 인광소자
}

\author{
장지근 ${ }^{\dagger}$ 신상배 · 신현관 · 김원기 · 유상욱 · 장호정 · 공명선* - 이준엽** \\ 단국대학교 전자공학과 \\ *단국대학교 화학과, **단국대학교 고분자공학과
}

\section{High Efficiency Green Phosphorescent Organic Light Emitting Devices using the Emission Layer of $\left(\mathrm{TCTA} / \mathrm{TCTA}_{1 / 3} \mathrm{TAZ}_{2 / 3} / \mathrm{TAZ}\right): \operatorname{Ir}(\mathrm{ppy})_{3}$}

\author{
Ji-Geun Jang ${ }^{\dagger}$, Sang-Baie Shin, Hyun-Kwan Shin, Won-Ki Kim, Sang-Ouk Ryu, Ho-Jung Chang, \\ Myoung-Seon Gong* and Jun-Yeob Lee** \\ Department of Electronics Eng., Dankook University, Chungnam 330-714, Korea \\ *Department of Chemistry, Dankook University, Chungnam 330-714, Korea \\ **Department of Polymer Sci. and Eng., Dankook University, Kyeonggi 448-701, Korea
}

(2008년 4월 16일 접수 : 2008년 6월 3일 최종수정 : 2008년 6월 4일 채택)

\begin{abstract}
We have fabricated and evaluated newNew high high-efficiency green green-light light-emitting phosphorescent devices with an emission layer of $\left[\mathrm{TCTA} / \mathrm{TCTA}_{1 / 3} \mathrm{TAZ}_{2 / 3} / \mathrm{TAZ}\right]: \operatorname{Ir}(\mathrm{ppy})_{3}$ were fabricated and evaluated, and compared the electroluminescence characteristics of these devices were compared with the conventional phosphorescent devices with emission layers of $\left(\mathrm{TCTA}_{1 / 3} \mathrm{TAZ}_{2 / 3}\right): \operatorname{Ir}(\mathrm{ppy})_{3}$ and (TCTA/ TAZ) : Ir(ppy). The current density, luminance, and current efficiency of the a device with an emission layer of $\left(80 \AA \text {-TCTA } / 90^{\circ} \AA \text {-TCTA } 1 / 3 \mathrm{TAZ}_{2 / 3} / 130 \AA \text {-TAZ) }: 10 \% \text {-Ir(ppy) }\right)_{3}$ were $95 \mathrm{~mA} / \mathrm{cm}^{2}, 25000 \mathrm{~cd} / \mathrm{m}^{2}$, and $27 \mathrm{~cd} / \mathrm{A}$ at an applied voltage of $10 \mathrm{~V}$, respectively. The maximum current efficiency was $52 \mathrm{~cd} / \mathrm{A}$ under the a luminance value of $400 \mathrm{~cd} / \mathrm{m}^{2}$. The peak wavelength and FWHM (FWHM (full width at half maximum) in the electroluminescence spectral were $513 \mathrm{~nm}$ and $65 \mathrm{~nm}$, respectively. The color coordinate was $(0.30,0.62)$ on the CIE (Commission Internationale de I'Eclairage) chart. Under the a luminance of $15000 \mathrm{~cd} / \mathrm{m}^{2}$, the current

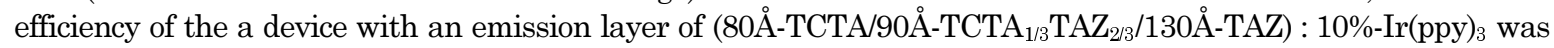
$34 \mathrm{~cd} / \mathrm{A}$, which has beenshowed an improvement of improved 1.7 and 1.4 times compared to those of the devices

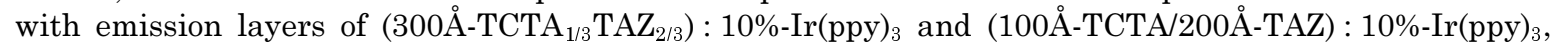
respectively.
\end{abstract}

Key words PhOLED, double hosts, current efficiency, TCTA, TAZ.

\section{1. 서 론}

인광 유기발광소자(phosphprescent organic light emitting devices, PhOLEDs)는 기본적으로 기판(유리, 플라스틱 등) 과 상부 및 하부 전극(양극 및 음극), 그리고 두 전극 사 이에 유기물이 삽입된 구조를 갖는다. 유기물은 보통 다층 형태로 정공수송층(HTL, hole transport layer)/발광층 (EML, emissive layer)/정공차단층 $(\mathrm{HBL}$, hole blocking layer)/전자수송층(ETL electron tansport layer)으로 구성 된다. 발광층의 유기물로는 단일 재료를 사용하기보다 호 스트-도펀트(host-dopant) 구성을 일반적으로 이용한다. 이 러한 구조에서는 캐리어들이 전극에서 발광층으로 직접

Corresponding author

E-Mail : semicgk@dankook.ac.kr (J. G. Jang)
주입되지 않고 캐리어 수송층을 통과하여 단계적으로 전 송됨으로 구동 전압이 낮아진다. 다층 구조에서는 발광 층으로 주입된 전자와 정공이 이웃 전극으로 이동할 때, $\mathrm{EML}$ 가장자리 부근에서 반대 극성의 캐리어 수송층에 의 해 이동이 제한됨으로, 엑시톤(exciton)의 생성이 발광층 에 속박되어 발광 효율이 높아진다.

$\mathrm{PhOLEDs}$ 에서는 일중항과 삼중항 엑시톤 모두로부터 빛 을 낼 수 있어, 내부 양자효율이 이론적으로 $100 \%$ 에 이 르지만, 실제 소자에서는 캐리어의 주입 손실과, 비 발 광성 엑시톤의 형성, 삼중간-삼중항 소멸 등으로 인해 발 광 효율이 크게 감소된다. ${ }^{1-3)}$ 또한 인광 소자의 발광층 에서 형성된 삼중항 엑시톤은 상대적으로 긴 수명을 가 져 EML 영역을 지나 다른 영역으로 확산할 수 있다. 삼중항 엑시톤의 확산은 $\mathrm{EML}$ 영역 바깥에서 에너지 전 이를 일으키거나 비발광성 소멸을 가져와 발광 효율과 색 
순도가 저하된다. 따라서 고효율 인광 소자를 제작하기 위해서는 발광층의 구성(재료, 두께, 도핑 농도 등)을 잘 설계하고,엑시톤 보호층을 설치하여 삼중항 엑시톤의 확산 손실을 방지할 수 있어야 한다. ${ }^{4-6)}$

PhOLEDs의 발광층 구성에서 단일 호스트를 이용하면 이 호스트가 보통 전자와 정공 중 어느 한 종류의 캐리 어를 선택적으로 잘 이동시켜 엑시톤 생성이 $\mathrm{EML}$ 영역 의 가장자리에서 발생한다. 이러한 현상은 소자의 발광 효율과 색 순도 저하를 초래하게 된다. 이에 따라 최근 에는 전자전달성이 우수한 호스트와 정공전달성이 우수 한 두 가지 호스트를 혼합하여 사용하거나 이들의 적층 구조를 이용한 PhOLEDs가 연구되고 있다. ${ }^{7-9)}$ 이중 호스 트를 이용한 혼합 구조와 적층 구조는 각각 발광층의 전 체 영역에서와 발광층의 이종 경계가 있는 중심 영역에 서 주로 엑시톤이 형성되므로 캐리어의 주입 손실과 삼 중항 엑시톤의 확산 손실을 어느 정도 방지할 수 있다 는 장점이 있다. 그러나 단순 혼합 구조에서는 발광층 가 장자리에서 발생하는 삼중항 엑시톤의 확산 손실을 완전 히 방지하기 어렵고, 적층 구조에서는 엑시톤 형성이 발 광층의 이종접합 부근에서 제한되는 문제점이 있다.

본 연구에서는 기존의 인광 소자가 갖는 낮은 효율, 짧 은 수명 등의 문제점들을 해결할 수 있는 새로운 구조로
TCTA-TAZ (TCTA[4,4',4"-tris (N-carbazolyl)-triphenylamine], TAZ [3-phenyl-4-(1"naphthyl)-5-phenyl-1, 2, 4triazole]) 이중 호스트 사이에 $\mathrm{TCTA}_{1 / 3} \mathrm{TAZ}_{2 / 3}$ 혼합 영역 을 갖는 녹색 인광 유기발광다이오드를 처음으로 제작하 고, 이들의 전계발광 특성을 조사하였다. 또한, 이중 호 스트간 혼합 영역을 갖는 구조 $\left(\mathrm{TCTA} / \mathrm{TCTA}_{1 / 3} \mathrm{TAZ}_{2 / 3} /\right.$ $\mathrm{TAZ}): \operatorname{Ir}(\mathrm{ppy})_{3}$ [tris(2-phenylpyridine)iridium(III)]의 우수 성을 알아보기 위해 전체 발광층의 두께를 일정하게 두 고 기존의 단순 혼합 $\left[\left(\mathrm{TCTA}_{1 / 3} \mathrm{TAZ}_{2 / 3}\right): \operatorname{Ir}(\mathrm{ppy})_{3}\right]$ 및 이중 적층 [(TCTA/TAZ) $\left.: \operatorname{Ir}(\mathrm{ppy})_{3}\right]$ 구조를 갖는 소자들을 함께 제작하여 이들의 특성을 비교하였다. 실험 소자들은 양 극과 음극 사이에 2-TNATA/NPB/EML/BCP/SFC-137의 기본 구조를 갖는다.

\section{2. 실험 방법}

$10 \Omega / \square$ 의 면저항(sheet resistance)과 $90 \%$ 이상의 광 투 과도를 갖는 $150 \mathrm{~nm}$ 두께의 ITO (Indium Tin Oxide)가 코팅된 유리 기판으로부터 양극 전극을 패터닝(patterning) 하고 아세톤, 메탄올, 이소프로필 알코올에 순차적으로 초 음파 세정 공정을 실시하였다. 이 후 $100^{\circ} \mathrm{C}$ 의 진공 오븐 에서 10 분간 건조한 후, 시료를 플라스마 처리실로 옮겨,

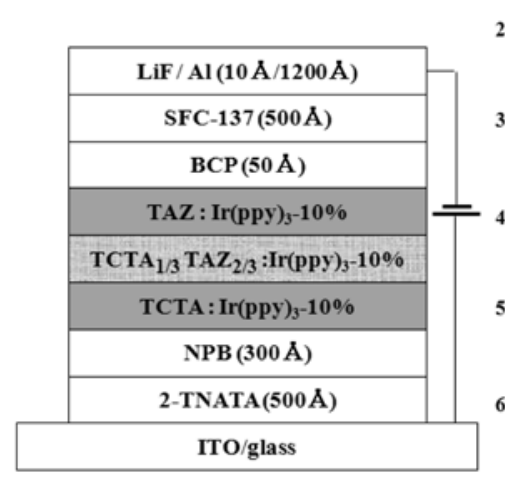

(a)

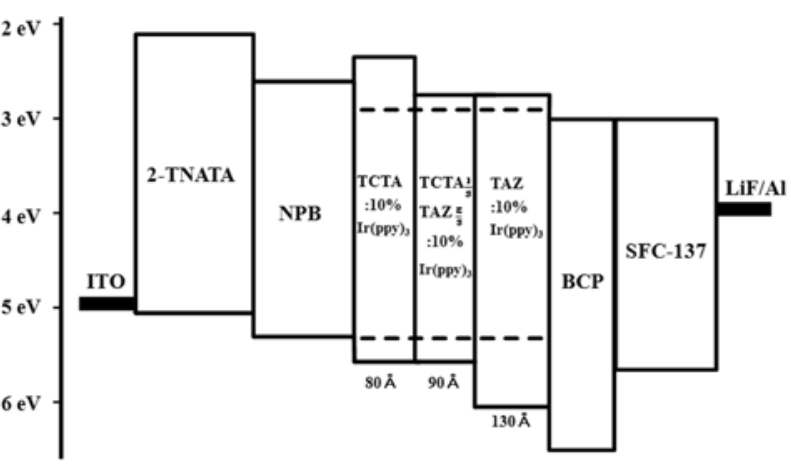

(b)

Fig. 1. The green PhOLED with a mixed layer between double hosts in the emission layer : (a) cross-section view and (b) energy band.

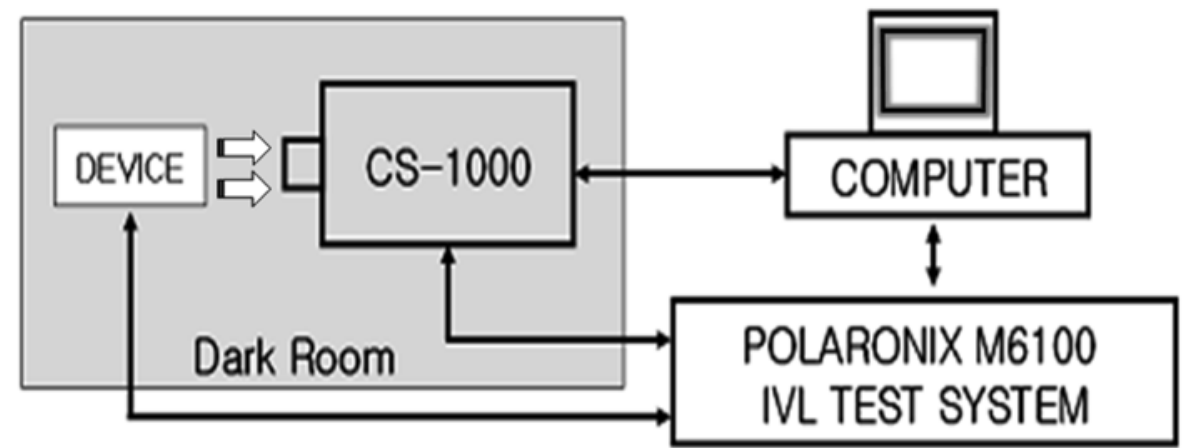

Fig. 2. Schematic diagram of measurement system with Polaronix M6100 and CS-1000. 
$\mathrm{O}_{2} / \mathrm{Ar}=2 / 1,8 \mathrm{mTorr}, 200 \mathrm{~W}$ 의 조건으로 2 분간 플라스마 처리를 실시하였다. 유기 박막을 증착하기 전의 플라스마 처리는 기판의 준비 과정에서 생긴 오염을 제거하고 유 기물과 ITO 사이 계면 접착력 향상 및 ITO의 일함수를 증가시켜 양극과 정공주입층과의 전위장벽을 낮추어 준다. 박막 형성 공정으로는 먼저 정공주입층으로 $500 \AA$ 두께 의 2-TNATA를 증착한 후 정공수송층으로 $300 \AA$ 두께의 $\mathrm{NPB}$ 를 증착하였다. 다음으로 발광층의 형성에서는 전체 호스트의 두께를 $300 \AA$ 으로 일정하게 유지하면서 단순 혼 합 구조(시료 1)에서는 TCTA와 TAZ를 $1: 2$ 로 혼합한 $300 \AA-\mathrm{TCTA}_{1 / 3} \mathrm{TAZ}_{2 / 3}$ 층을, 적층 구조(시료 2)에서는 100 $\AA-\mathrm{TCTA} / 200 \AA \AA-\mathrm{TAZ}$ 층을, 이중 호스트간 혼합 영역을 갖는 구조(시료 3)에서는 $8 \AA-\mathrm{TCTA} / 90 \AA-\mathrm{TCTA}_{1 / 3} \mathrm{TAZ}_{2 / 3} /$ $130 \AA$-TAZ 층을 증착하였다. 모든 발광층에서 $\operatorname{Ir}(\mathrm{ppy})_{3}$ 를 인광 도펀트로 사용하였고 호스트와 co-evaporation 방식 으로 도핑 농도를 $10 \%$ 로 유지하였다. 이 후 정공차단층 으로 $50 \AA$ 두께의 $\mathrm{BCP}$ 층을 두고, 전자수송층으로 $\mathrm{SFC}-$ 137 을 $500 \AA$ 두께로 증착한 후, 시료를 금속 증착실로 옮 겨 $\mathrm{LiF}$ 와 $\mathrm{Al}$ 을 각각 $10 \AA$ 과 $1200 \AA$ 두께로 진공 증착하여 음극 전극을 형성하였다. Fig. 1은 이중 호스트간 혼합 영역을 갖는 소자의 단면도 (a)와 에너지 밴드 (b)를 보 여주고 있다.

외부의 빛을 차단할 수 있는 암실에서 Polaronix $\mathrm{M} 6100$ 장치와 CS-1000 분광복사계(spectro-radiometer)를 이용하여 제작된 소자의 전계발광 특성을 측정하였으며, 측정 시스템의 장치도를 Fig. 2에 나타내었다.

\section{3. 결과 및 고찰}

소자 제작에서 발광층의 구성에 따라 시료들을 단순 혼 합 소자, 이중 적층 소자, 이중 호스트간 혼합영역을 갖 는 소자로 구분하고, 이들의 J-V-L(current density-voltageluminance), EL spectral 분포 및 $\mathrm{CIE}$ (Commission Internationale de I'Eclairage) 색 좌표를 측정하였다.

Fig. 3과 Fig. 4는 제작된 소자의 전류밀도-전압(J-V) 및 휘도-전압 $(\mathrm{L}-\mathrm{V})$ 그래프이다. Fig. 3 의 전류 밀도는 단순 혼 합 소자와 이중 호스트 사이 혼합 영역을 갖는 소자에서 거의 비슷하게 나타났으며, 이중 적층 소자에서 상대적 으로 낮은 전류 흐름을 나타내었다. 이중 적층 소자에서 낮은 전류밀도 특성은 TCTA 영역에서 정공의 흐름과 연 관된 소자의 전기저항 증가에 기인하는 것으로 판단된다. 이에 비해 Fig. 4의 발광 휘도는 이중 호스트간 혼합 영 역을 갖는 소자에서 가장 높게 나타났다. $10 \mathrm{~cd} / \mathrm{m}^{2}$ 상태 에서 측정된 임계전압은 모든 시료들에서 약 $3.5 \mathrm{~V}$ 로 나 타났으며, $10 \mathrm{~V}$ 의 인가전압에서 측정된 소자들의 전류밀도 와 휘도는 이중 호스트간 혼합 영역을 갖는 소자의 경우 $95 \mathrm{~mA} / \mathrm{cm}^{2}$ 와 $25000 \mathrm{~cd} / \mathrm{m}^{2}$ 로, 단순 혼합 소자의 경우

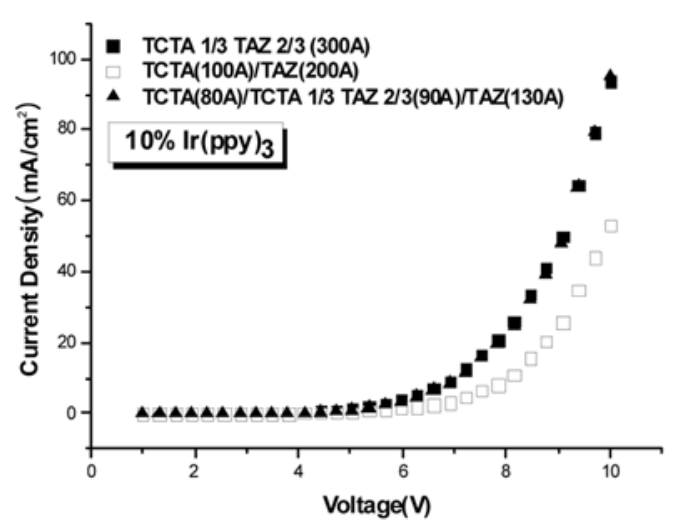

Fig. 3. Current density-voltage characteristics of the fabricated devices.

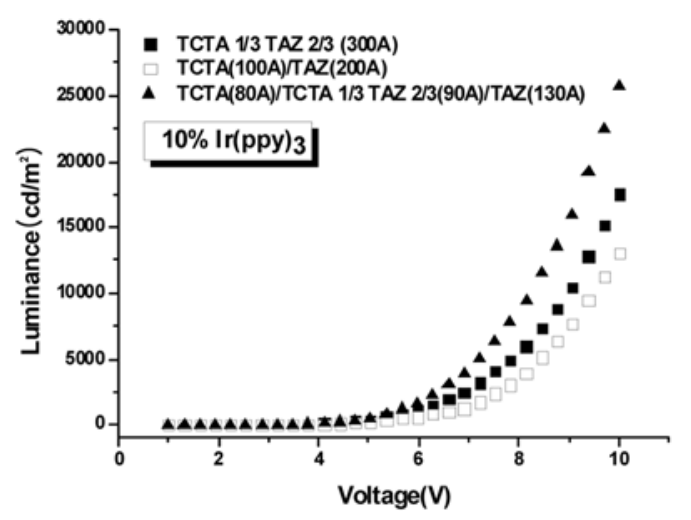

Fig. 4. Luminance-voltage characteristics of the fabricated devices.

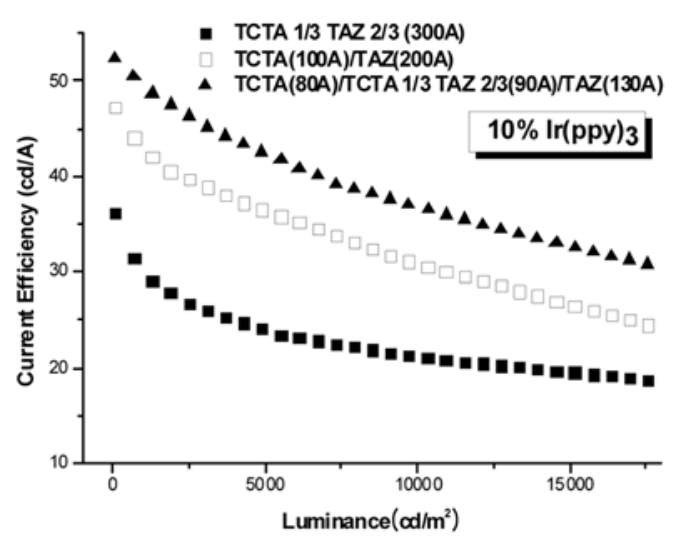

Fig. 5. Current efficiency-luminance characteristics of the fabricated devices.

$94 \mathrm{~mA} / \mathrm{cm}^{2}$ 와 $17500 \mathrm{~cd} / \mathrm{m}^{2}$ 로, 이중 적층 소자의 경우 53 $\mathrm{mA} / \mathrm{cm}^{2}$ 와 $13000 \mathrm{~cd} / \mathrm{m}^{2}$ 로 나타났다.

소자의 전류효율은 인가전압에 관계없이 소자의 발광 특성을 알아보는 데 매우 유용한 파라미터이다. 전류 효 율은 $\mathrm{L} / \mathrm{J}$ 의 관계식으로 표현되며, 여기서 $\mathrm{L}$ 과 $\mathrm{J}$ 는 각각 소자에 흐르는 전류밀도와 휘도를 나타낸다. 
Table 1. Electroluminescence characteristics of the fabricated devices

\begin{tabular}{|c|c|c|c|c|}
\hline \multirow{2}{*}{ Parameter } & \multirow{2}{*}{ Dimension } & \multicolumn{3}{|c|}{ Samples } \\
\hline & & 1 & 2 & 3 \\
\hline Host Structures $\left(\operatorname{Ir}(\mathrm{ppy})_{3}: 10 \%\right)$ & - & $\mathrm{TCTA}_{1 / 3} \mathrm{TAZ}_{2 / 3}(300 \AA)$ & $\begin{array}{c}\operatorname{TCTA}(100 \AA) / \\
\operatorname{TAZ}(200 \AA)\end{array}$ & $\begin{array}{c}\operatorname{TCTA}(80 \AA) / \\
\operatorname{TCTA}_{1 / 3} \mathrm{TAZ}_{2 / 3} / \\
\operatorname{TAZ}(130 \AA)\end{array}$ \\
\hline Current Density (at $10 \mathrm{~V}$ ) & $\mathrm{mA} / \mathrm{cm}^{2}$ & 94 & 53 & 95 \\
\hline Luminance (at $10 \mathrm{~V}$ ) & $\mathrm{cd} / \mathrm{m}^{2}$ & 17500 & 13000 & 25000 \\
\hline Current Efficiency (at $15000 \mathrm{~cd} / \mathrm{m}^{2}$ ) & $\mathrm{cd} / \mathrm{A}$ & 20 & 27 & 34 \\
\hline Max. Current Efficiency & $\mathrm{cd} / \mathrm{A}$ & $36\left(\right.$ at $\left.80 \mathrm{~cd} / \mathrm{m}^{2}\right)$ & $47\left(\right.$ at $\left.200 \mathrm{~cd} / \mathrm{m}^{2}\right)$ & $52\left(\right.$ at $\left.400 \mathrm{~cd} / \mathrm{m}^{2}\right)$ \\
\hline Central Wavelength & $\mathrm{nm}$ & 512 & 515 & 513 \\
\hline CIE Coordinate & $(\mathrm{x}, \mathrm{y})$ & $(0.32,0.61)$ & $(0.31,0.62)$ & $(0.30,0.62)$ \\
\hline
\end{tabular}

$$
\eta[c d / A]=\frac{L\left[c d / m^{2}\right]}{J\left[A / m^{2}\right]}
$$

전류 효율은 J-V-L 측정값으로부터 식 (1) 을 이용하여 계산할 수 있으며, 전류효율 대 휘도 특성의 그래프를 Fig. 5에 나타내었다. Fig. 5 를 살펴보면, 주어진 소자에 서 전류효율은 전반적으로 휘도가 증가할수록 다소 감소 되는 특성을 보이고 있다. 인광 소자의 고휘도 상태에서 발광 효율의 감소는 삼중간-삼중항 소멸(triplet- triplet annihilation)에 주로 기인하는 것으로 알려져 있다. ${ }^{10)}$ 제 작된 소자들에서 가장 우수한 효율 특성은 이중 호스트 간 혼합 영역을 갖는 소자에서 얻어졌으며, 최대 전류효 율은 $400 \mathrm{~cd} / \mathrm{m}^{2}$ 의 휘도 상태에서 약 $52 \mathrm{~cd} / \mathrm{A}$ 로 나타났다. Fig. 5 의 $15000 \mathrm{~cd} / \mathrm{m}^{2}$ 휘도 상태에서, 이중 호스트 간 혼 합 영역을 갖는 소자의 전류효율은 $34 \mathrm{~cd} / \mathrm{A}$ 로, 단순 혼합 구조를 갖는 소자의 경우보다 $(\eta=20 \mathrm{~cd} / \mathrm{A})$ 약 1.7 배의, 이중 적층 구조를 갖는 소자의 경우보다 $(\eta=27 \mathrm{~cd} / \mathrm{A})$ 약 1.3 배의 발광 효율 개선을 가져왔다.

본 연구에서 얻어진 $52 \mathrm{~cd} / \mathrm{A}$ 의 전류효율은 pin-구조의 인광 소자를 제외하고는 ${ }^{11,12)}$ 지금까지 보고된 PhOLEDs 에서 가장 높은 값의 하나로 평가된다. ${ }^{13,14)}$ 이중 호스트 간 혼합 영역을 갖는 구조는 독창적이며, 종래의 단순 혼 합 구조나 이중 적층 구조로 부터 새로운 물질의 추가나 복잡한 공정의 도입 없이 단순히 증착 프로그래밍의 조 절만으로 소자 제작이 가능하다. 이중 호스트 간 혼합 영 역을 갖는 소자의 발광 효율 개선은 발광층의 적절한 구조 설계에 의한 캐리어 전달의 수월성, 중심 부근에서 충분 한 엑시톤 생성 영역의 확보 및 발광층 외부로 엑시톤 의 손실 방지 등이 복합되어 얻어지는 것으로 판단된다. 발광 층 구성에 따른 제작된 소자들의 전계발광 특성을 Table 1에 요약하였다.

Fig. 6과 Fig. 7은 각각 이중 호스트 간 혼합 영역을 갖는 소자의 전계발광 스펙트럼과 $\mathrm{CIE}$ 색 좌표이다. Fig. 6의 전계발광 스펙트럼에서 발광 피크는 $513 \mathrm{~nm}$ 의 중심

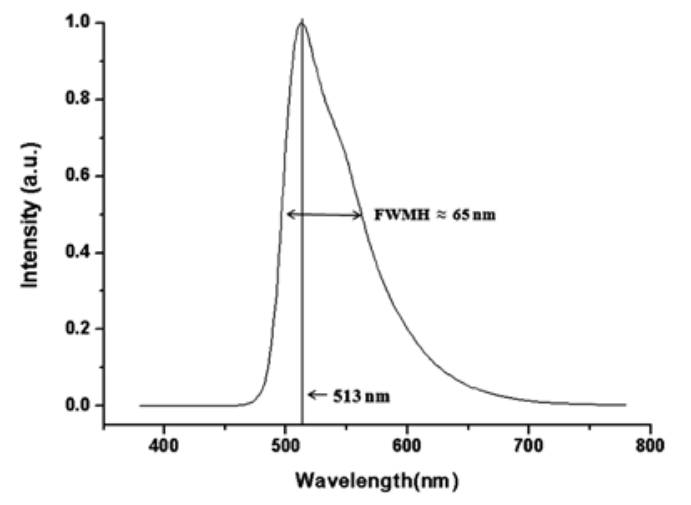

Fig. 6. EL spectra of the PhOLED with (TCTA/TCTA $1 / 3 \mathrm{TAZ}_{2 / 3} /$ $\mathrm{TAZ}): \operatorname{Ir}(\mathrm{ppy})_{3}$ emission layer at an applied voltage of $10 \mathrm{~V}$.

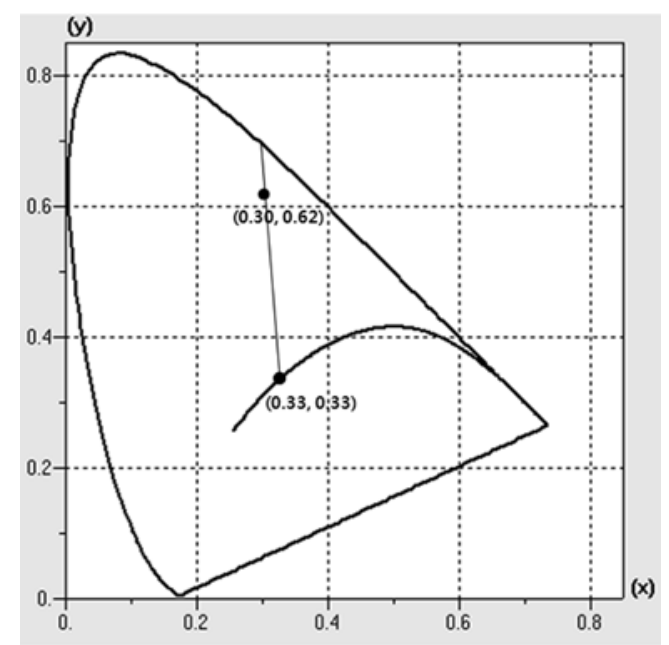

Fig. 7. CIE coordinate chart of the PhOLED with (TCTA/ $\left.\mathrm{TCTA}_{1 / 3} \mathrm{TAZ}_{2 / 3} / \mathrm{TAZ}\right): \operatorname{Ir}(\text { ppy })_{3}$ emission layer at an applied voltage of $10 \mathrm{~V}$.

파장과 약 $65 \mathrm{~nm}$ 의 $\mathrm{FWHM}$ 을 갖는 전형적 $\operatorname{Ir}(\mathrm{ppy})_{3}$-삼중 항 발광 특성을 나타내었다. Fig. 7의 $\mathrm{CIE}$ 도표 상에서 색 좌표는 $(0.30,0.62)$ 으로 나타나며, 약 $80 \%$ 의 색 순도를 
보여주고 있다. 전계발광 스펙트럼과 $\mathrm{CIE}$ 좌표는 제작 된 모든 시료들에서 거의 유사하게 나타났다.

\section{4. 결 론}

본 연구에서는 고효율 녹색 인광소자를 개발하기 위해 새로운 이중 호스트 발광층의 구조로 두 호스트(TCTA, $\mathrm{TAZ})$ 사이 이들의 혼합층 $\left(\mathrm{TCTA}_{1 / 3} \mathrm{TAZ}_{2 / 3}\right)$ 을 갖는 녹색 인광 유기발광다이오드를 제안하고 그 특성을 평가하였다.

실험에서는 새로운 구조의 소자에 대한 전계발광 특성 의 개선을 알아보기 위해, 소자의 기본 구조를 ITO/2$\operatorname{TNATA}(500 \AA) / \mathrm{NPB}(300 \AA) / \mathrm{EML}(300 \AA) / \mathrm{BCP}(50 \AA) /$ $\mathrm{SFC} 137(500 \AA) / \mathrm{LiF}(10 \AA) / \mathrm{Al}$ 로 나타내고, 발광층의 구성 에 따라 단순 혼합 소자 $\left[\left(300 \AA-\mathrm{TCTA}_{1 / 3} \mathrm{TAZ}_{2 / 3}\right): 10 \%\right.$ -

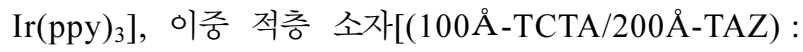
$\left.10 \%-\operatorname{Ir}(\mathrm{ppy})_{3}\right]$, 이중 호스트 간 혼합 영역을 갖는 소자

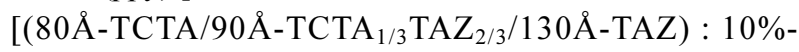
$\left.\operatorname{Ir}(\mathrm{ppy})_{3}\right]$ 로 구분하고 이들의 전계발광 특성을 비교하였다. 실험 결과, 이중 호스트 간 혼합 영역을 갖는 소자의 전류밀도, 휘도 그리고 전류효율은 $10 \mathrm{~V}$ 의 인가전압에서 각각 $95 \mathrm{~mA} / \mathrm{cm}^{2}, 25000 \mathrm{~cd} / \mathrm{m}^{2}, 27 \mathrm{~cd} / \mathrm{A}$ 로 나타났으며, 최대 전류효율은 $400 \mathrm{~cd} / \mathrm{m}^{2}$ 의 휘도 상태에서 약 $52 \mathrm{~cd} / \mathrm{A}$ 로 나타났다. 또한 발광 스펙트럼의 EL (electroluminescence) 피크는 $513 \mathrm{~nm}$ 의 중심 파장과 약 $65 \mathrm{~nm}$ 의 FWHM을 나 타내었으며, $\mathrm{CIE}$ 도표 상에서 색 좌표는 $(0.30,0.62)$ 로 나 타났다. 실험 소자에서 전계발광 특성은 이중 호스트 간 혼합 영역을 갖는 소자에서 가장 우수하게 나타났으며, $15000 \mathrm{~cd} / \mathrm{m}^{2}$ 휘도 상태에서 전류효율은 $34 \mathrm{~cd} / \mathrm{A}$ 로, 단순 혼합 구조를 갖는 소자의 경우보다 약 1.7 배의, 이중 적 층 구조를 갖는 소자의 경우보다 약 1.3 배의 발광효율 개선을 나타내었다.

이중 호스트 간 혼합 영역을 갖는 구조는 종래의 단 순 혼합 구조나 이중 적층 구조로부터 새로운 물질의 추 가나 복잡한 공정의 도입 없이 단순히 증착 프로그래밍 의 조절만으로 소자 제작이 가능함으로 고효율 $\mathrm{PhOLED}$ 기술의 산업적 응용이 기대된다.

\section{감사의 글}

본 연구는 지식경제부 지방기술혁신사업 (RTI04-01-02) 지원으로 수행되었으며, 이에 감사를 드립니다.

\section{참 고 문 헌}

1. M. A. Baldo, D. F. O' Brien, Y. You, A. Shoustikov, S. Sibley, M. R. Thomson and S. R. Forrest, Nature, 395, 151 (1998).

2. C. Adachi, M. A. Baldo, M. E. Thompson and S. R. Forrest, J. of Appl. Physics, 90, 5048 (2001).

3. S. H. Kim, J. S. Jang, K. S Yook, J. Y. Lee, M. S. Gong, S. Ryu, G. K. Chang and H. J. Chang, J. of Appl. Phys. Lett., 103, 054502 (2008).

4. C. Adachi, T. Tsutsui and S. Saito, Appl. Phys. Lett., 57, 531 (1990).

5. M. Ikai, S. Tokito, Y. Sakamoto, T. Suzuki and Y. Taga, Appl. Phys. Lett., 79, 156 (2001).

6. V. Adamovich, S. R. Cordero, P. I. Djurovich, A. Tamayo, M. E. Thompson, B. Andrade and S. R. Forrest, Org. Electron., 4, 77 (2003).

7. M. B. Khalifa, D. Vaufrey and J. Tardy, Organic Electronics, 5, 187 (2004).

8. J. Sun, X. Zhu, X. Yu, M. Wong and H. S. Kwok, SID 07 DIGEST, 826 (2007).

9. T. Zheng and W. Choy, J. Phys. D: Appl. Phys., 41, 055103 (2008).

10. R. Farchioni and G. Gross, Organic Electronic Materials, p. 428, Springer Series in Materials Science, Berlin, (2001).

11. G. He, M. Pfeiffer, K. Leo, M. Hofmann, J. Birnstock, R. Pudzich and J. Salbeck, Appl. Phys. Lett., 85, 3911 (2004).

12. M. Toerker, M. Eritt, Ch. May, J. Amelung, C. Luber, R. Hermann, Ch. Zschippang, Y. Tomita and K. Leo, Proc. SID International Symposium, 37(2), 1471 (2006).

13. K. Goushi, Y. Kawamura, H. Sasabem and C Adachi, Jpn. J. of. Appl. Phys. Lett., 43, L937 (2004).

14. B. J. Chen, X. W. Sun and K. R. Sarma, Mat. Sci. Eng. B., 139, 192 (2007). 